\section{Cleavage of Human High Molecular Weight Kininogen Markedly Enhances Its Coagulant Activity \\ Evidence That This Molecule Exists as a Procofactor}

Cheryl F. Scott, Lee D. Silver, Marc Schapira, and Robert W. Colman

Thrombosis Research Center and the Hematology/Oncology Section of the Department of Medicine, Temple University Health Sciences Center, Philadelphia, Pennsylvania 19140
A

(HMW)-kininact. High molecular weight kininogen blood coagulation, accelerates the activation of Factor XII, prekallikrein, and Factor XI on a negatively charged surface. Although prekallikrein and Factor XI circulate as a complex with HMW-kininogen, no physical association has been demonstrated between Factor XII and HMW-kininogen, nor has the order of adsorption to surfaces of these proteins been fully clarified. In this report, we explore the requirements for adsorption of HMWkininogen to a clot-promoting surface (kaolin), in purified systems, as well as in normal plasma and plasma genetically deficient in each of the proteins of the contact system. The fraction of each coagulant protein associated with the kaolin pellet was determined by measuring the difference in coagulant activity between the initial sample and supernatants after incubation with kaolin, or by directly quantifying the amount of ${ }^{125} \mathrm{I}-\mathrm{HMW}$-kininogen that was associated with the kaolin pellet.

In normal plasma, the adsorption of HMW-kininogen to kaolin increased as the quantity of kaolin was increased in the incubation mixture. However, the HMW-kininogen in Factor XII-deficient plasma did not absorb appreciably to kaolin. Furthermore, the quantity of HMW-kininogen

Portions of this work were presented at the 55th session of the American Heart Association, November 15-18, 1982, Dallas, TX and were published in abstract form (1982, Circulation, 66:295).

Address all correspondence to Dr. Colman. 1983.

Received for publication 15 July 1982 and in revised form 7 December

J. Clin. Invest.

(c) The American Society for Clinical Investigation, Inc. 0021-9738/84/04/0954/09\$1.00

Volume 73, April 1984, 954-962 from prekallikrein-deficient plasma that adsorbed to kaolin was decreased as compared with normal plasma. These observations suggested that HMW-kininogen in plasma must be altered by a reaction involving both Factor XII and prekallikrein in order for HMW-kininogen to adsorb to kaolin, and to express its coagulant activity. Subsequently, the consequence of the inability of HMWkininogen to associate with a negatively charged surface results in decreased surface activation. This assessment was derived from the further observation of the lack of prekallikrein adsorption and the diminished Factor XI adsorption in both Factor XII-deficient and HMW-kininogen-deficient plasmas, since these two zymogens (prekallikrein and Factor XI) are transported to a negatively charged surface in complex with HMW-kininogen. The percentage of HMW-kininogen coagulant activity that adsorbed to kaolin closely correlated $(r=0.98$, slope $=0.97$ ) with the amount of ${ }^{125}$ I-HMW-kininogen adsorbed, suggesting that adsorption of HMW-kininogen results in the expression of its coagulant activity.

Since kallikrein, which is known to cleave HMWkininogen, is generated when kaolin is added to plasma, we tested the hypothesis that proteolysis by kallikrein was responsible for the enhanced adsorption of HMW-kininogen to kaolin. When purified HMW-kininogen was incubated with purified kallikrein, its ability to adsorb to kaolin increased with time of digestion until a maximum was reached. Moreover, ${ }^{125}$ I-HMW-kininogen, after cleavage by kallikrein, had markedly increased affinity for kaolin than the uncleaved starting material. Furthermore, fibrinogen, at plasma concentration $(3 \mathrm{mg} / \mathrm{ml})$, markedly curtailed the adsorption of a mixture of cleaved and uncleaved HMW-kininogen to kaolin, but was unable to prevent fully cleaved HMW-kininogen from adsorbing to the kaolin. Addition of purified kallikrein to Factor 
XII-deficient plasma, which bypasses Factor XII-dependent contact-activation, amplified the ability of its HMWkininogen to adsorb to kaolin.

These observations indicate that HMW-kininogen is a procofactor that is activated by kallikrein, a product of a reaction which it accelerates. This cleavage, which enhances its association with a clot-promoting surface in a plasma environment, is an event that is necessary for expression of its cofactor activity. These interactions would allow coordination of HMW-kininogen adsorption with the adsorption of Factor XII, which adsorbs independently of cleavage, to the same negatively charged surface.

\section{Introduction}

High molecular weight kininogen (HMW $)^{1}$-kininogen functions as a cofactor in the initiation of surface-activated intrinsic blood coagulation by circulating in complexes with either Factor XI (1) or prekallikrein (2), thereby facilitating their optimal orientation on a negatively charged surface (3-7). Here, the zymogens are converted to their corresponding active enzymes (Factor XIa and kallikrein) by activated Factor XII (8-10). The kallikrein that is generated converts additional Factor XII to Factor XIIa, thereby amplifying the contact-activated system of blood coagulation (8). Both intact HMW-kininogen or its light chain $\left(M_{\mathrm{r}}=45,000\right)$ form complexes with Factor XIa and kallikrein (11), curtailing their rate of inactivation by plasma protease inhibitors (12-14). Prekallikrein can also be converted to kallikrein in the absence of a negatively charged surface, by Factor XII fragments (15), a reaction not requiring HMW-kininogen (16). The influence of solution and surface activation of the intrinsic pathway of blood coagulation, as well as the exact sequence of events in these reactions, however, is still not completely understood.

Physical studies of the interaction of plasma with hydrophilic (clot-promoting) surfaces such as glass, revealed that when normal plasma is applied to that surface, fibrinogen is antigenically

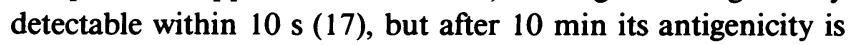
lost. Concomitantly, HMW-kininogen is not initially antigenically detectable; but at $10 \mathrm{~min}$ it is detectable (18). Furthermore, in HMW-kininogen-deficient plasma, fibrinogen remains detectable after $10 \mathrm{~min}$ and in Factor XII-deficient plasma, where contact-activation cannot occur, much of the fibrinogen remains detectable on the clot-promoting surface after $10 \mathrm{~min}$ (19). Since no differences could be determined by physical measurements of the degree of protein thickness on the surface before or after the interaction of fibrinogen and HMW-kininogen, these data suggest that HMW kininogen binds to, replaces, or competes with fibrinogen on the clot-promoting surface (18).

This investigation was designed to assess the ability of various

1. Abbreviations used in this paper: HMW, high molecular weight; HSA, human serum albumin; PAGE, polyacrylamide gel electrophoresis. proteolytic digestion products of HMW-kininogen to interact with the clot-promoting surface, kaolin. To evaluate the behavior of this cofactor in the plasma environment, studies were performed in normal and contact factor-deficient plasma, as well as in purified systems containing plasma proteins. Evidence will be presented that proteolysis of HMW-kininogen amplifies its adsorption to kaolin and that plasma concentrations of fibrinogen, but not albumin, can drastically curtail the association of uncleaved HMW-kininogen with kaolin, while still allowing adsorption of cleaved HMW-kininogen.

\section{Methods}

Sodium dodecyl sulfate (SDS), methylene bis-acrylamide, acrylamide, high and low molecular weight standards $(220,000,130,000,94,000$, $68,000,43,000,30,000,21,000$ ), and Dowex AG-1B were purchased from Bio-Rad Laboratories, Richmond, CA. Prestained molecular weight standards $(200,000,92,000,68,000,43,000,25,700,18,400)$ were obtained from BRL, Bethesda, MD. Soybean trypsin inhibitor, lysozyme, human serum albumin (HSA), bovine gamma globulin, and trypsin were from Sigma Chemical Co., St. Louis, MO. Kodak XAR x-ray film was purchased from Reliance X-ray, Glenside, PA; Kaolin (acid washed), glass tubes $(6 \times 50 \mathrm{~mm})$, and polyethylene glycol 8000 were from Fisher Scientific Co., King of Prussia, PA; inosithin (mixed soybean phospholipids) was from Associated Concentrates, New York. Human fibrinogen (Kabi $90 \%$ clottable) was obtained from Helena Laboratories, Beaumont, TX; microcentrifuge tubes 699 and 690, from Sarstedt, Inc., Princeton, NJ. $\left[{ }^{14} \mathrm{C}\right.$ ]inulin and $\mathrm{Na}^{125}$ I were obtained from New England Nuclear, Boston, MA; antiserum to high molecular weight kininogen light chain, from Miles Biochemicals, Elkhart, IN; antiserum to bradykinin was a gift of Dr. David Proud. Tyrosine-8-bradykinin was purchased from Peninsula Laboratories, Inc., Belmont, CA; slab gel electrophoretic apparatus model SE 600, from Hoefer Scientific Instruments, San Francisco, CA. Iodogen was obtained from Pierce Chemical Co., Rockford, IL; Coomassie Brilliant Blue R-250 and LKB rack gamma counter, from LKB Instruments, Rockville, MD; Beckman liquid scintillation counter LS 8000, from Beckman Instruments, Inc., Fullerton, CA; Kodak RP X-Omat automated processor, from Eastman Kodak Co., Rochester, NY (courtesy of Dept. of Neuroradiology, Temple University Hospital).

Plasma. Normal pooled plasma, used as a reference standard, was purchased from George King Biomedicals, Inc., Overland Park, KS. Plasmas deficient either in Factor XI or total kininogen (20) were donated directly to us. Factor XII-deficient plasma was kindly supplied by Dr. Margaret Johnson, Wilmington, DE. Prekallikrein-deficient plasma was graciously supplied by Dr. Charles Abildgaard, Davis, CA. Aliquots of several other Factor XII-deficient plasma were a gift from Mr. George King (George King Biomedicals, Inc.).

Assay of HMW-kininogen coagulant activity (kaolin-activated partial thromboplasin time). $100 \mu \mathrm{l}$ of total kininogen-deficient plasma, $100 \mu \mathrm{l}$ of $20 \mathrm{mM}$ Tris-Cl, $\mathrm{pH} 7.4$, containing $0.15 \mathrm{M} \mathrm{NaCl}, 100 \mu$ l of kaolin $(5 \mathrm{mg} / \mathrm{ml}$ in saline), and $100 \mu \mathrm{l}$ of $0.2 \%$ inosithin in buffer were mixed. Normal plasma $(10,5,2$, or $1 \mu \mathrm{l})$ was added and incubated at $37^{\circ} \mathrm{C}$ for $8.5 \mathrm{~min} .100 \mu \mathrm{l}$ of $30 \mathrm{mM} \mathrm{CaCl}$ was added and coagulation time was measured. This procedure was used to generate a standard curve (log-log relationship). Samples for analysis were assayed, under the same conditions, using 5 or $10 \mu \mathrm{l}$ of sample and the data were expressed as percentage of normal pooled plasma. One unit $(U)$ is the amount of activity in $1 \mathrm{ml}$ of normal pooled plasma.

Purified proteins. Kallikrein was prepared by activation of purified 
prekallikrein by Factor XII fragments (21). The activation was stopped with purified corn trypsin inhibitor $(50 \mu \mathrm{g} / \mathrm{ml})(22)$ which was a kind gift of Dr. Edward Kirby and Patrick McDevitt of this institution. The preparation contained no measurable Factor XI, XIa, XII, XIIa, plasminogen, or plasmin as determined by coagulant and amidolytic assays. Two different kallikrein preparations were used. The first preparation was free of IgG and the second contained $10-20 \mathrm{mg} \mathrm{IgG/mg} \mathrm{kallikrein.}$ Both preparations yielded similar results in the experiments described.

HMW-kininogen was prepared by the method of Kerbiriou and Griffin (23) and was primarily a single band of $M_{\mathrm{r}}=120,000$ on nonreduced SDS-polyacrylamide gel electrophoresis (PAGE). Upon reduction, $75-90 \%$ remained $M_{\mathrm{r}}=120,000$, as assessed by scanning densitometry of the gels.

Fibrinogen was purified from fresh human citrated plasma, as previously described (24). Thrombin-coagulable protein was $95 \%$ of the total. The preparation of purified fibrinogen was freed of plasminogen by passing it through a lysine-sepharose column. SDS-PAGE in $3.5 \%$ gels demonstrated the presence of one homogenous fibrinogen band and the absence of von Willebrand's factor and fibronectin. This fibrinogen was used in all experiments that were performed with purified proteins.

Kaolin adsorption experiments. Kaolin (10 mg) was suspended in 1

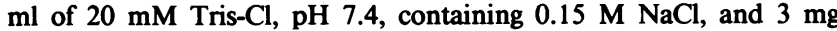
fibrinogen, at $23^{\circ} \mathrm{C}$. Various volumes of the suspension were transferred to 0.4-ml microcentrifuge tubes, centrifuged in an Eppendorf microcentrifuge for $1 \mathrm{~min}$ at $12,000 \mathrm{~g}$ at $23^{\circ} \mathrm{C}$, and the supernatants were discarded. The prepared kaolin pellets were retained for use as a negatively charged surface. In some experiments, kaolin $(10 \mathrm{mg} / \mathrm{ml})$ was added directly to the above-mentioned buffer containing fibrinogen, before the addition of the other reactants. Buffers containing fibrinogen $(3 \mathrm{mg} /$ $\mathrm{ml})$, HSA $(30 \mathrm{mg} / \mathrm{ml})$, and HMW-kininogen, were prepared. In the experiments where plasma was adsorbed to kaolin, it was directly added to a prepared kaolin pellet. One-half of each solution or plasma sample was transferred to the tube containing the kaolin pellet, mixed, and incubated at $23^{\circ} \mathrm{C}$ for the times indicated. The presence of fibrinogen prevented adsorptive losses during transfer (16). After centrifugation, the supernatants were transferred to clean tubes. The original sample and supernatants from the kaolin pellets were then assayed for coagulant activity. The percent coagulant activity adsorbed to the kaolin was calculated as (initial activity - residual supernatant activity)/(initial activity) $\times 100$.

Using $\left[{ }^{14} \mathrm{C}\right]$ inulin, we found that $10-25 \%$ of the fluid was trapped by the kaolin, when the kaolin pellets were prepared with buffer. Furthermore, it was difficult to efficiently remove the buffer without removing some kaolin. However, when fibrinogen was added to the kaolin, the trapped fluid decreased to $3 \%$ and kaolin could be easily separated. An assessment of the amount of plasma trapped by the kaolin pellet after incubation was determined by incubating $99 \mu$ l plasma and $1 \mu$ l $\left[{ }^{14} \mathrm{C}\right]$ inulin with kaolin pellets ranging in weight from 125 to $500 \mu \mathrm{g}$. After incubation for $15 \mathrm{~min}$ at $23^{\circ} \mathrm{C}$, the pellets were centrifuged. The starting material, supernatants, and pellets were counted for radioactivity. Trapped fluid averaged 3\% for each amount of kaolin used and therefore no corrections were necessary.

To obtain an independent determination of the amount of coagulant proteins associated with the kaolin pellets, normal plasma was incubated with kaolin for various times. The pellets were washed six times with buffer, resuspended in the initial sample volume, and assayed for prekallikrein, Factor XI, or high molecular weight kininogen coagulant activity. The activity in the pellet was always less than the difference between starting material and supernatant in agreement with a previous study (25) showing inhibition of the enzymes in the coagulant assay by kaolin.
Therefore, in all subsequent experiments, we measured the difference between starting material and supernatant in order to determine the percent coagulant protein associated with the kaolin pellet.

Determination of HMW-kininogen antigen in plasma. Radial immunodiffusion (26) was performed by using an antibody to HMWkininogen light chain.

Preparation and analysis of cleaved HMW-kininogen. HMW-kininogen, in $0.15 \mathrm{M}$ Tris-acetate, $\mathrm{pH}$ 8.0, was incubated with kallikrein at $37^{\circ} \mathrm{C}$. At specified times, aliquots were transferred to tubes containing soybean trypsin inhibitor (6.5-fold molar excess compared with kallikrein) in order to stop the cleavage process. To monitor the distribution of the cleaved product, 5- $\mu \mathrm{l}$ aliquots were removed from each tube and added to glass tubes $6 \times 50 \mathrm{~mm}$, containing $70 \mu 1 \mathrm{H}_{2} \mathrm{O}$ and $25 \mu \mathrm{l}$ buffer containing $0.4 \mathrm{M}$ Tris- $\mathrm{Cl}, \mathrm{pH} 6.8$, and $8 \%$ SDS. The samples were reduced with 2-mercaptoethanol $(0.8 \mathrm{M})$ and either boiled for $5 \mathrm{~min}$ or incubated overnight at $37^{\circ} \mathrm{C}$. Polyacrylamide gel electrophoresis was carried out in the presence of SDS on $10 \%$ slab gels $(16 \times 18 \mathrm{~mm}$ plates $)$ according to the method of Laemmli (27). The gels were run at $36 \mathrm{~mA} /$ gel for $4 \frac{1}{2} \mathrm{~h}$ or overnight at $7.5 \mathrm{~mA} / \mathrm{gel}$ and stained in $0.5 \%$ Coomassie Brilliant Blue R-250 in 5:5:1 $\left(\mathrm{CH}_{3} \mathrm{OH} / \mathrm{H}_{2} \mathrm{O} / \mathrm{CH}_{3} \mathrm{COOH}\right)$.

Stained gels and autoradiograms for selected experiments were scanned using a SD 3000 Spectrodensitometer (Schoeffel Instrument Div., Kratos, Inc., Westwood, NJ). The relative peak areas were quantified by weighing tracings on standard paper.

Radiolabeling of HMW-kininogen. $125 \mu \mathrm{g}$ of purified HMW-kininogen was radiolabeled by a minor modification of the Iodogen method (28) at $\mathrm{pH} 8.0$ in the presence of $0.75 \mathrm{M} \mathrm{NaCl}$. After stopping the reaction with sodium metabisulfite $(50 \mu \mathrm{g} / \mathrm{ml})$, the labeled material was gel filtered on a $(0.5 \times 10 \mathrm{~cm}) \mathrm{G}-50$ column, equilibrated with $50 \mathrm{mM}$ sodium acetate buffer, $\mathrm{pH} 5.2,0.15 \mathrm{M} \mathrm{NaCl}$, and $1 \%$ polyethylene glycol 8000 , in order to remove the free ${ }^{125} \mathrm{I}$. The peak contained $14 \%$ of the total radioactivity. The specific radioactivity of the peak tube was 1.4 $\times 10^{6} \mathrm{cpm} / \mu \mathrm{g}$. The HMW-kininogen coagulant activity was monitored during the radiolabeling procedure and was not altered.

Radiolabeling of tyrosine-8-bradykinin. Tyrosine-8-bradykinin was iodinated by the chloramine T method (29). The labeled peptide was separated from the free iodine by elution from Dowex AG-1B with distilled water. The peak material was diluted 1:4 in 0.2 M Tris acetate:0.01 M Na${ }_{2}$ EDTA, pH 6.4, containing $1 \mathrm{mg} / \mathrm{ml}$ lysozyme (Trislysozyme buffer) and stored at $-70^{\circ} \mathrm{C}$.

Measurement of bradykinin release. Bradykinin was measured using a radioimmunoassay according to the method of Proud et al. (29). To prepare individual samples for assay, $3 \mu \mathrm{l}$ of the sample was added to $97 \mu \mathrm{l}$ of Tris-lysozyme buffer. The sample was mixed and then $400 \mu \mathrm{l}$ $95 \%$ ethanol was added. The sample was placed at $4^{\circ} \mathrm{C}$ for at least 10 min before centrifugation at $12,000 \mathrm{~g}$ for $5 \mathrm{~min}$. Subsequently, the supernatant was removed and the pellet reextracted with ethanol, spun at $12,000 \mathrm{~g}$, and the supernatants combined. This sample was applied to a $3 \mathrm{ml}$ QAE A-50 Sephadex column $\left(4^{\circ} \mathrm{C}, 0.0075 \mathrm{M}\right.$ Tris buffer, $\mathrm{pH}$ 8.0) and the bradykinin eluted with the same buffer. Percent recovery for the procedure was $82 \%$. Radioimmunoassay (RIA) was performed as outlined previously (29) using a high affinity bradykinin antisera at a concentration of 1:100,000. Duplicate samples were incubated at $4^{\circ} \mathrm{C}$ for $18 \mathrm{~h}$. Polyethylene glycol 8000 precipitation was used to separate free from bound bradykinin. Results were calculated from a log-logit plot of bradykinin, ranging from ( 0 to $500 \mathrm{pg} / \mathrm{ml})$, vs. relative binding.

\section{Results}

Effect of kaolin concentration on the adsorption of contact factors in normal and contact factor-deficient plasma. When normal 
plasma was incubated with kaolin, and the supernatant assayed for HMW-kininogen coagulant activity, HMW-kininogen adsorption to kaolin directly increased with increasing kaolin concentration (Fig. $1 A$ ). The adsorption of this cofactor in Factor XI-deficient plasma was similar to what was observed with normal plasma. In contrast, adsorption of HMW-kininogen was decreased in prekallikrein-deficient plasma. In Factor XII-deficient plasma, little or no adsorption of HMW-kininogen was observed. We found, however, that during prolonged storage or freezing and thawing of the Factor XII-deficient plasma, an increased amount of HMW-kininogen adsorbed to kaolin. Therefore, for subsequent experiments, we used a batch of Factor XII-deficient plasma which was freshly collected and snap-frozen (George King Biomedicals, Inc.).

Factor XII was found to adsorb to the same extent in all plasma samples tested (Fig. $1 B$ ), in agreement with the suggestion (3) that its adsorption is not dependent upon its cleavage or the cleavage of any other plasma proteins.

Prekallikrein (Fig. $2 A$ ) from either normal or Factor XIdeficient plasma was similar in its adsorption characteristics with maximal adsorption occurring at a kaolin concentration of $1.25 \mathrm{mg} / \mathrm{ml}$. Prekallikrein adsorption to kaolin from HMWkininogen-deficient or Factor XII-deficient plasma, was $<1 \%$. Thus, prekallikrein adsorption to kaolin in plasma not only requires HMW-kininogen but also Factor XII.

At the lowest concentration of kaolin studied, $81 \%$ of the Factor XI (Fig. 2 B) from normal plasma was adsorbed, and at the highest kaolin concentration, $93 \%$ was adsorbed. In contrast, the Factor XI which was adsorbed onto kaolin from HMWkininogen-deficient plasma ranged from 14 to $24 \%$ and from Factor XII-deficient plasma, ranged from 9 to $37 \%$ of normal.

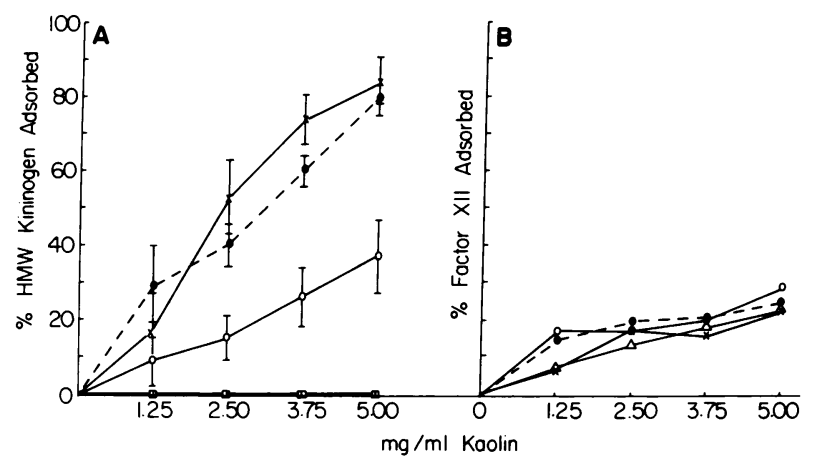

Figure 1. Effect of kaolin concentration on adsorption of HMW-kininogen $(A)$ and Factor XII $(B)$ from deficient plasmas. Kaolin pellets, $0.125-0.5 \mathrm{mg}$, were prepared as in Methods. $100 \mu \mathrm{l}$ of normal $(\bullet)$, Factor XII-deficient ( $\square$ ), Factor XI deficient $(x)$, prekallikrein-deficient $(0)$, or HMW-kininogen-deficient $(\Delta)$ plasma was then suspended and incubated with the kaolin for $15 \mathrm{~min}$ at $23^{\circ} \mathrm{C}$. The starting material and supernatants were assayed for HMW-kininogen and Factor XII coagulant activity and the percentage adsorbed was calculated by difference. The data represent the mean \pm SD of three to six experiments.

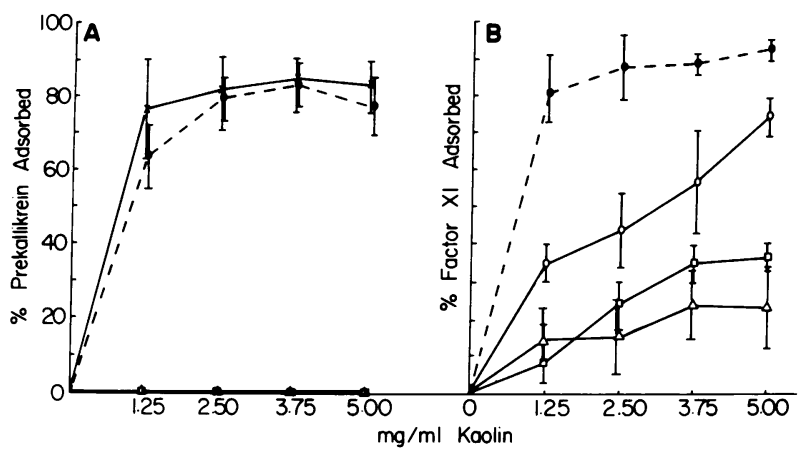

Figure 2. Effect of kaolin concentration on adsorption of prekallikrein $(A)$ and Factor $\mathrm{XI}(B)$ from deficient plasmas. Kaolin pellets, $0.125-0.5 \mathrm{mg}$, were prepared as in Methods. $100 \mu \mathrm{l}$ of normal $(\bullet)$, Factor XII-deficient ( $\square$ ), Factor XI-deficient $(x)$, prekallikrein-deficient $(0)$, or HMW-kininogen deficient $(\Delta)$ plasma was then suspended and incubated with the kaolin for $15 \mathrm{~min}$ at $23^{\circ} \mathrm{C}$. The starting material and supernatants were assayed for prekallikrein and Factor XI coagulant activity and the percentage adsorbed was calculated by difference. The data represent the mean $\pm S D$ of three to six experiments.

The amount of Factor XI that adsorbed to kaolin in prekallikrein-deficient plasma was also diminished, as compared with normal, especially at the lowest concentration, where only $35 \%$ was adsorbed and reached a maximum of $74 \%$. Thus, prekallikrein and Factor XI adsorption depended not only on HMWkininogen but also on Factor XII.

These findings indicate that both prekallikrein and Factor XII are involved in an alteration of HMW-kininogen that increases its adsorption to kaolin in plasma and ultimately the adsorption of Factor XI.

Relationship between adsorption of HMW-kininogen coagulant activity and adsorption of ${ }^{125} I-H M W$-kininogen to kaolin. To confirm that the decrease in plasma HMW-kininogen coagulant activity, after exposure to kaolin, was actually due to physical removal of the protein by kaolin, we performed two experiments to analyze the behavior of HMW-kininogen. In the first study, the residual HMW-kininogen in the supernatant, after incubation with kaolin, was determined by its coagulant activity (Fig. 3, $x$ axis). We also measured the adsorption of HMW-kininogen to kaolin by determining the percent ${ }^{125} \mathrm{I}$ HMW-kininogen directly associated with the kaolin pellet (Fig. 3, $y$ axis). Each group of samples was generated by incubating plasma (normal or prekallikrein-deficient) with kaolin, for various times. We observed an excellent correlation $(r=0.97)$ between the two sets of data, and a slope of 0.98 , indicating that the decrease in coagulant activity was a direct result of physical removal of the HMW-kininogen by the kaolin. Moreover, using ${ }^{125} \mathrm{I}-\mathrm{HMW}$-kininogen, there was close agreement between the sum of the supernatant and pellet radioactivity as compared with the radioactivity of the starting material.

These observations were reproduced in a second study by incubating normal plasma with kaolin and assaying the super- 


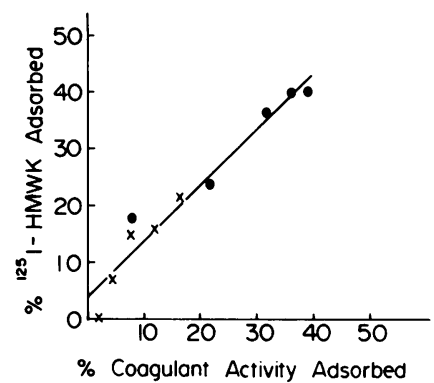
sample and supernatant was assayed for HMW-kininogen coagulant activity (as in Fig. 2). Prekallikrein-deficient plasma was used for the lower values, and normal plasma was used for the higher values. In a parallel experiment, ${ }^{125} \mathrm{I}-\mathrm{HMW}$-kininogen $(5 \mu \mathrm{l}), 75 \mu \mathrm{l}$ saline, and $320 \mu \mathrm{l}$ of normal plasma $(\bullet)$ or prekallikrein-deficient plasma $(x)$ was mixed. $250 \mu$ l of each mixture was incubated with a precoated kaolin pellet $(625 \mu \mathrm{g})$ and $50 \mu \mathrm{l}$ was removed and centrifuged at $2,5,10$, 15 , and $20 \mathrm{~min}$. The starting material, supernatants, and pellets were counted for gamma radioactivity. After calculating the percentage of radioactivity adsorbed, linear regression analysis was performed by correlating the results with that obtained for the functional (coagulant) data. $(r=0.97$; slope $=0.98$; intercept $=4.3 \%)$.

natant for coagulant activity as well as antigen (using antibody to light chain of HMW-kininogen). A correlation coefficient of 0.98 and a slope of 0.97 were observed when the data were analyzed in that experiment (data not shown).

From the data of Fig. 1 and Fig. 3, it is evident HMWkininogen was physically adsorbed to kaolin in normal plasma, but not from Factor XII-deficient plasma. It thus appears that an alteration in the HMW-kininogen molecule enabled HMWkininogen to adsorb to kaolin in a plasma environment. Factor $\mathrm{XII}$ is known to be activated on exposure to kaolin and then to activate prekallikrein to kallikrein, which in turn cleaves HMW-kininogen. Therefore, we investigated the possibility that cleavage of HMW-kininogen promoted its adsorption to kaolin.

Cleavage of purified HMW-kininogen by kallikrein. To assess the distribution of cleavage products of HMW-kininogen as a function of time, we incubated HMW-kininogen, that was $>90 \%$ intact, with kallikrein for various times, and stopped the reaction with soybean trypsin inhibitor (Fig. 4). The disappearance of the $120,000-M_{\mathrm{r}}$ species was followed by the appearance of a heavy chain $\left(M_{\mathrm{r}}=65,000\right)$ reaching a maximum at $20 \mathrm{~min}$, and a light chain $\left(M_{\mathrm{r}}=56,000\right)$ reaching a maximum at 15 min. A small amount of degraded light chain $\left(M_{\mathrm{r}}=45,000\right)$, as described by Mori and Nagasawa (30), was observed between 0 and $60 \mathrm{~min}$. After $60 \mathrm{~min}$, when the $56,000-M_{\mathrm{r}}$ species began to decrease, the $45,000-M_{\mathrm{r}}$ species rapidly increased. The reciprocal relationship of the $56,000-M_{\mathrm{r}}$ light chain and 45,000 $M_{\mathrm{r}}$ degraded light chain suggested that the $56,000-M_{\mathrm{r}}$ species was a short-lived intermediate and the $45,000-M_{\mathrm{r}}$ species was an end-product of the HMW-kininogen proteolysis.

Effect of purified fibrinogen on the adsorption of uncleaved and cleaved HMW-kininogen as determined by coagulant ac- tivity. Previous studies (17-19) have suggested that fibrinogen may be a plasma component that affects HMW-kininogen adsorption to activating surfaces. This observation allowed us to assess the adsorption to kaolin in a purified system of virtually intact HMW-kininogen ( $90 \%$ of protein $120,000-M_{\mathrm{r}}$ ), HMWkininogen that was partially cleaved $(65 \%$ of protein 120,000 $M_{\mathrm{r}}$ ), and HMW-kininogen that was fully cleaved by kallikrein (no $120,000-M_{\mathrm{r}}$ component). Parallel experiments were performed in the absence (Fig. $5 \mathrm{~A}$ ) and presence (Fig. $5 \mathrm{~B}$ ) of fibrinogen at plasma concentrations $(3 \mathrm{mg} / \mathrm{ml})$. The $90 \%$ intact HMW-kininogen adsorbed to kaolin in the absence of fibrinogen to a limited extent. With cleavage, the extent of adsorption at a given kaolin concentration increased (Fig. $5 \mathrm{~A}$ ). The presence of fibrinogen decreased the adsorption of the $90 \%$ intact and $65 \%$ intact HMW-kininogen but had no effect on fully cleaved HMW-kininogen (Fig. 5 B). Thus, cleavage of HMW-kininogen amplified its adsorption to kaolin in the presence of a concentration of fibrinogen similar to that in plasma.

The actual amount of fibrinogen $(3.9 \mathrm{mg} / \mathrm{ml})$ adsorbed to $12.5 \mathrm{mg}$ of kaolin was determined by measuring the fibrinogen $\left(E_{280}^{1 \%} \mathrm{~nm}=13.6\right)$ before and after centrifugation of the kaolin pellet. The adsorbed fibrinogen was $44 \mu \mathrm{g}$ or $17.6 \mu \mathrm{g} / 5 \mathrm{mg}$ kaolin. From Fig. 5, $4.8 \mu \mathrm{g}$ of uncleaved HMW-kininogen was

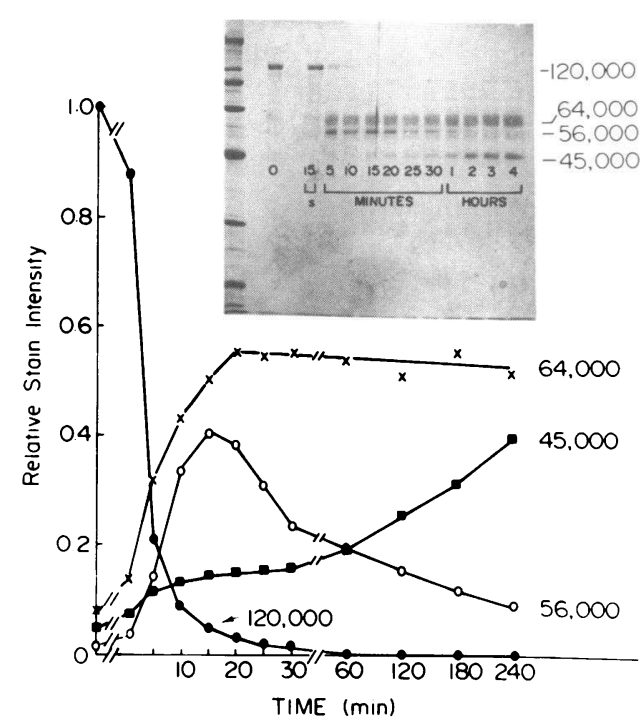

Figure 4. Cleavage of HMW-kininogen by kallikrein. HMW-kininogen $(65 \mu \mathrm{g})$ was incubated with kallikrein $(1.4 \mu \mathrm{g})$ in a final volume of $30 \mu \mathrm{l}$ (weight ratio of kallikrein to HMW-kininogen of 1:46). At the times indicated, $2 \mu \mathrm{l}$ was transferred to a tube containing $5 \mu \mathrm{l} 2$ mercaptoethanol, sample buffer, and water in a final volume of 100 $\mu$ l. The samples were each incubated in the 2 -mercaptoethanol mixture for $15 \mathrm{~min}$ at $37^{\circ} \mathrm{C}$ in order to destroy the kallikrein activity. Subsequently, all samples were incubated at $37^{\circ} \mathrm{C}$ overnight to complete the reduction process. $50 \mu \mathrm{l}$ of each reduced sample was then subjected to SDS-PAGE, as described in Methods. The standards utilized were a mixture of high and low molecular weight proteins obtained from Bio-Rad Laboratories (see Methods). 


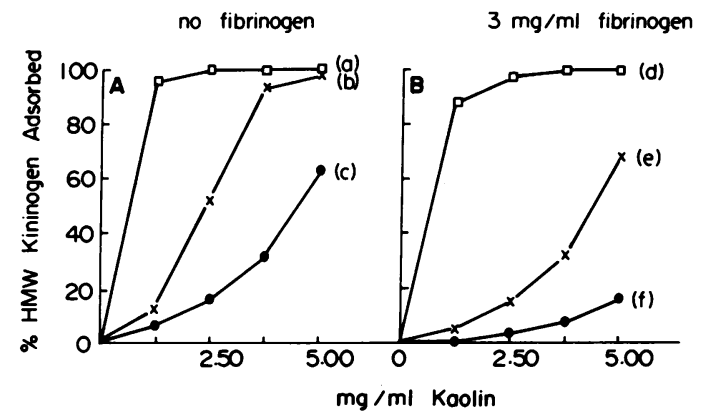

Figure 5. Effect of fibrinogen on adsorption of intact and cleaved HMW-kininogen. Three preparations of HMW kininogen were used. The first preparation contained $90 \%$ of the $M_{\mathrm{r}}=120,000$ band $(c$ and $f$ ). A second preparation contained $65 \%$ of the $M_{\mathrm{r}}=120,000$ band $(b$ and $e$ ) and the third preparation was fully cleaved by kallikrein $(a$ and $d) .100 \mu l$ of each preparation, at $1 \mathrm{U} / \mathrm{ml}$, was incubated in the absence $(A)$ or presence $(B)$ of $3 \mathrm{mg} / \mathrm{ml}$ purified plasminogen-free fibrinogen, with kaolin $(0-5 \mathrm{mg} / \mathrm{ml} \mathrm{final} \mathrm{concentration)}$ for $10 \mathrm{~min}$ at $23^{\circ} \mathrm{C}$. The starting material and supernatants from the kaolin pellets were assayed for HMW-kininogen coagulant activity. Each point is the average of duplicate determinations and the figure is representive of two to three similar experiments.

adsorbed in the absence of fibrinogen, whereas in the presence of fibrinogen, only $1.8 \mu \mathrm{g}$ was adsorbed, which is a difference of $3.0 \mu \mathrm{g}$. Substitution of $30 \mathrm{mg} / \mathrm{ml}$ HSA for fibrinogen resulted in similar results to those with buffer alone (data not shown). Therefore, fibrinogen displayed specificity in its ability to prevent uncleaved HMW-kininogen from adsorbing to kaolin.

Effect of cleavage on adsorption of ${ }^{125} I-H M W$-kininogen to kaolin. To ascertain which cleavage events were critical for the adsorption of HMW-kininogen to kaolin, radiolabeled HMW kininogen was incubated for various times with plasma kallikrein (Fig. 6). The cleavage profile (data not shown) was similar to Fig. 4 except that the rate of cleavage was slower, owing to a lower ratio of kallikrein to HMW-kininogen in the incubation mixture. As cleavage progressed, increasing amounts of HMW kininogen were found to adsorb to kaolin, until maximal adsorption was observed between 3 and $4 \mathrm{~h}$ of incubation. The maximal adsorption followed the maximal formation of the $56,000-M_{\mathrm{r}}$ species and also paralleled bradykinin release. Thus, the first two cleavages of HMW-kininogen by kallikrein greatly enhance its ability to adsorb to kaolin at plasma concentrations of fibrinogen.

Determination of ${ }^{125}$ I-HMW-kininogen that adsorbed to kaolin in the presence of fibrinogen. To identify and quantify the actual species of HMW-kininogen that adsorbed to kaolin, various amounts of ${ }^{125} \mathrm{I}-\mathrm{HMW}$-kininogen starting material (Fig. 7 a) or ${ }^{125} \mathrm{I}-\mathrm{HMW}$-kininogen that was partially cleaved by kallikrein (Fig. 7 b), were mixed with fibrinogen and HSA and incubated with kaolin, in the presence and absence of a fivefold excess of unlabeled HMW-kininogen. A maximum of $2,600 \mathrm{cpm}(0.265$ $\mu \mathrm{g})$ from the starting material was associated with $100 \mu \mathrm{g}$ kaolin, and a similar amount of radioactivity was present in the pellet in the presence of additional fivefold excess unlabeled HMW kininogen (Fig. $7 a$ ). The radioactivity that was adsorbed to the kaolin could not be eluted by SDS. Moreover, the labeled HMWkininogen in the supernatant was uncleaved (Fig. $7 a$, inset).

In contrast, $18,000 \mathrm{cpm}(1.84 \mu \mathrm{g})$ from the cleaved HMWkininogen were associated with kaolin, and all but $2,500 \mathrm{cpm}$ (14\%) were displaced by the excess unlabeled, cleaved HMWkininogen (Fig. 7 b). The kaolin-associated material was then eluted with SDS and subjected to electrophoresis. The SDSextracted kaolin pellet Fig. $7 b$ (inset), contained $15 \%$ uncleaved HMW-kininogen $\left(M_{\mathrm{r}}=120,000\right)$, equivalent to the adsorption observed before the chase with unlabeled HMW kininogen and $85 \%$ cleavage products (heavy and light chains). The unadsorbed material, however, contained $85 \%$ uncleaved HMW-kininogen and $15 \%$ cleavage products. This experiment, in agreement with Fig. 5, suggests that cleavage of HMW-kininogen markedly amplifies its ability to adsorb to kaolin in the presence of fibrinogen, and that uncleaved HMW-kininogen has little to no ability to adsorb to a negatively charged surface, under such conditions.

Effect of kallikrein on the adsorption of HMW-kininogen from Factor XII-deficient plasma. To directly test the hypothesis

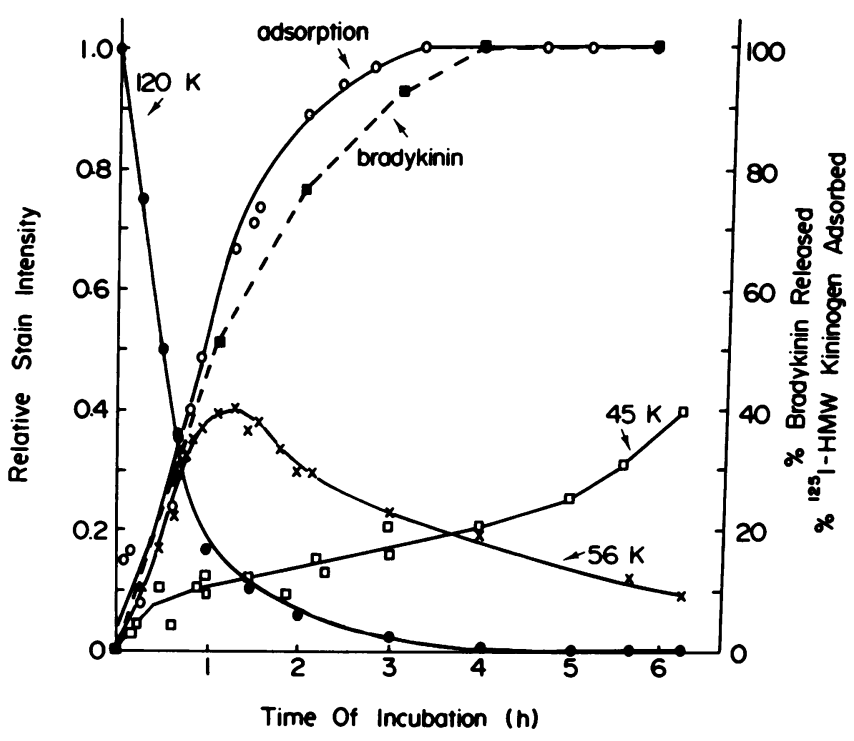

Figure 6. Kaolin adsorption of cleaved ${ }^{125} \mathrm{I}-\mathrm{HMW}$-kininogen in a purified system containing fibrinogen. Aliquots of cleaved HMW-kininogen $(3 \mu \mathrm{l})$ from a timed digest $(25 \mu \mathrm{g}$ kallikrein and $2,500 \mu \mathrm{g}$ HMW-kininogen in a final volume of $535 \mu \mathrm{l}$ ) were removed for bradykinin determination ( $(\bullet)$ after stopping the reaction with soybean trypsin inhibitor $(\mathbf{4 0} \mu \mathrm{g})$. Additional 3- $\mu \mathrm{l}$ aliquots were incubated with $97 \mu \mathrm{l}$ of fibrinogen $(3 \mathrm{mg} / \mathrm{ml})$ in buffer, and then $50 \mu \mathrm{l}$ of each mixture was added to $0.125 \mathrm{mg}$ prepared kaolin pellets for $6 \mathrm{~min}$ at $23^{\circ} \mathrm{C}$. The starting material and supernatants were counted for gamma radioactivity and the percentage of ${ }^{125} \mathrm{I}-\mathrm{HMW}$-kininogen adsorbed to kaolin was calculated (0). After SDS-PAGE, the percentage of each $M_{\mathrm{r}}$ form 120,000 (๑), 56,000 (×), 45,000 () was calculated after densitometric scanning of the stained gel (see Methods). 


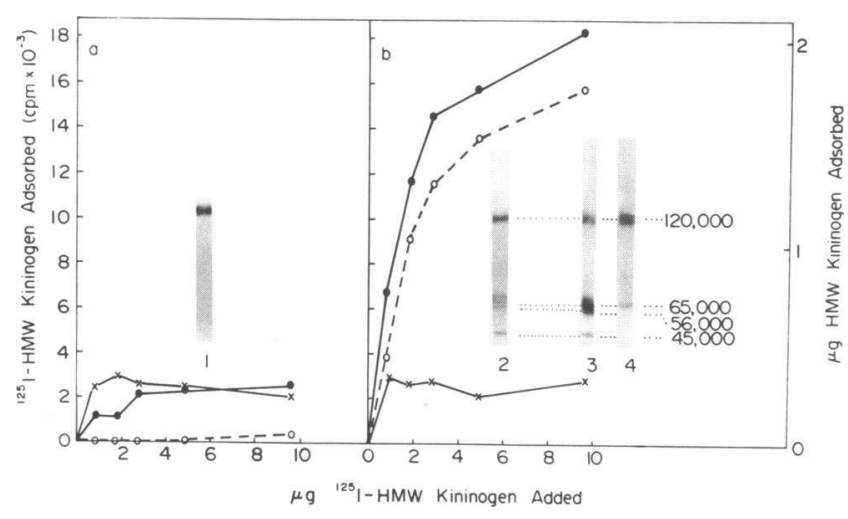

Figure 7. Effect of cleavage by kallikrein on the adsorption of ${ }^{125} \mathrm{I}$ HMW-kininogen to kaolin. Various amounts of ${ }^{125} \mathrm{I}-\mathrm{HMW}$-kininogen starting material $(a)$ were diluted with unlabeled HMW-kininogen $1: 120$ in order to reduce the specific radioactivity to $9,800 \mathrm{cpm} / \mu \mathrm{g}$. ${ }^{125}$ I-HMW-kininogen, which was incubated with kallikrein (1:48 wt/ wt) for $2 \mathrm{~h}$ at $37^{\circ} \mathrm{C}(b)$, was also incubated with $218 \mu \mathrm{g}$ fibrinogen, $2,180 \mu \mathrm{g}$ human serum albumin, and $100 \mu \mathrm{g}$ of kaolin at $23^{\circ} \mathrm{C}$ for 6 min in the presence and absence of an additional fivefold excess unlabeled HMW-kininogen. The samples were centrifuged at $12,000 \mathrm{~g}$ at $23^{\circ} \mathrm{C}$ for $1 \mathrm{~min}$ and the supernatants and pellets counted for radioactivity. The kaolin-associated radioactivity and amount of HMW-kininogen are plotted vs. the amount of HMW kininogen incubated. $\bullet,{ }^{125} \mathrm{I}$-HMW-kininogen alone; $\times,{ }^{125} \mathrm{I}$-HMW-kininogen plus unlabeled HMW-kininogen; $O$, specific adsorption (the difference between the above). (Inset) The pellets, obtained by incubating cleaved ${ }^{125} \mathrm{I}$-HMW-kininogen with kaolin, were washed with $100 \mu$ l saline three times and this wash, containing $<6 \%$ of the total radioactivity, was discarded. The pellets were then incubated for $10 \mathrm{~min}$ at $23^{\circ} \mathrm{C}$ with $1 \%$ SDS in Tris-Cl, pH 6.8. The soluble extracts as well as the unadsorbed material, were run reduced on a $10 \%$ SDS-PAGE, and an autoradiogram was performed at $-70^{\circ} \mathrm{C}$ and percentage of total radioactivity was calculated as in Methods. This photograph represents the $5 \mu \mathrm{g}{ }^{125} \mathrm{I}-\mathrm{HMW}$-kininogen sample. 1 , uncleaved starting material; 2, cleaved (partially) starting material; 3, SDS-extracted pellet; 4 , supernatant.

that kallikrein can render HMW-kininogen capable of adsorption to kaolin in a plasma environment, purified kallikrein was incubated with Factor XII-deficient plasma (Fig. 8) before the mixture was exposed to kaolin (curves a and c) and compared with normal plasma (curve b). At various times, a portion was removed and the supernatants were assayed for residual HMWkininogen coagulant activity. The amount of HMW-kininogen that adsorbed to kaolin increased with time of incubation to kaolin, unlike what occurred in the sample without kallikrein (curve d). Therefore, kallikrein can directly promote kaolin adsorption of HMW-kininogen in Factor XII-deficient plasma.

\section{Discussion}

The discovery that HMW-kininogen is an essential determinant of the rate of initiation of blood coagulation on in vitro surfaces opened up a new line of inquiry into the mechanism of contactactivated coagulation. Many of the reactions previously known to occur on negatively charged surfaces, including the reciprocal activation of Factor XII and prekallikrein, and the transformation of Factor XI into an active enzyme, are dramatically accelerated in the presence of HMW-kininogen (3-6). The observations that this cofactor forms complexes with prekallikrein (2) and Factor XI (1) led to the hypothesis that the binding to HMW-kininogen optimally positions these zymogens on clotpromoting surfaces for subsequent activation by Factor XIIa. However, since Factor XII adsorbs to negatively charges surfaces independently of HMW-kininogen (3) (Fig. 1 B), current concepts have not provided for coordination of the binding of this initiator of contact-activated coagulation with the cofactor, HMW-kininogen. We now present evidence that this cofactor exists as a procofactor, and that proteolysis by plasma kallikrein greatly augments its adsorption to a kaolin surface, in the presence of fibrinogen concentrations occurring in plasma (Figs. 6 and 7). Fibrinolysis cannot explain the ability of cleaved HMWkininogen to adsorb to kaolin, since in a purified system (Fig. 6), kallikrein (the only enzyme in the experiment) was inactivated before incubation with plasminogen-free fibrinogen and kaolin. We therefore conclude that not only is HMW-kininogen necessary for optimal positioning of the zymogens, prekallikrein, and Factor XI on a negatively charged surface but that in its cleaved form, is actually responsible for transporting the $z y-$ mogens or enzymes to the surface.

Purified uncleaved HMW-kininogen adsorbed to kaolin even in the presence of high concentrations of human albumin (30 $\mathrm{mg} / \mathrm{ml}$ ), but this adsorption was prevented by plasma concentrations of purified fibrinogen (Fig. 5). However, fibrinogen failed to prevent cleaved HMW-kininogen from adsorption to kaolin

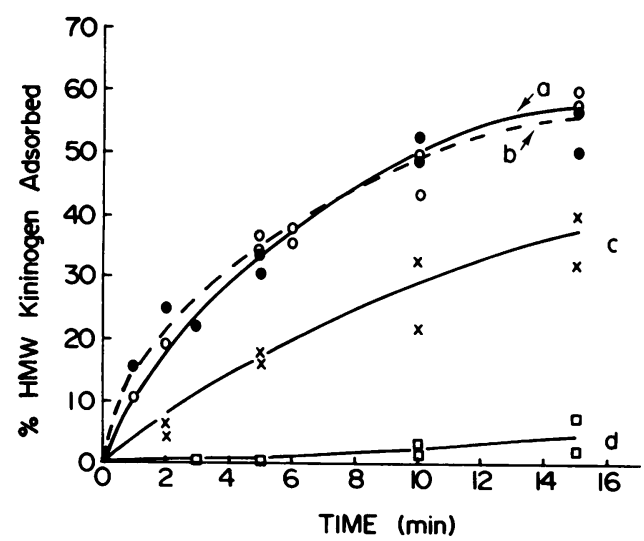

Figure 8. Effect of kallikrein on HMW-kininogen adsorption to kaolin in Factor XII-deficient plasma. Purified kallikrein $(0.92 \mathrm{U} / \mathrm{ml})$ $(a), 0.46 \mathrm{U} / \mathrm{ml}(c)$, or buffer $(d)$ was incubated with Factor XII-deficient plasma for $3 \mathrm{~min}$ before incubation with kaolin $(2.5 \mathrm{mg} / \mathrm{ml})$. At various times, $50-\mu \mathrm{l}$ aliquots were centrifuged. The starting material and supernatants were then assayed for HMW-kininogen coagulant activity. Normal plasma was included for comparison $(b)$. 
(Fig. 7). Since HMW-kininogen in plasma must interact with a negatively charged surface in the presence of $\sim 3 \mathrm{mg} / \mathrm{ml} \mathrm{fi}$ brinogen in order to become a cofactor for the activation of Factor XI and prekallikrein, a mechanism must be operative that permits HMW-kininogen to associate with the activating surface. Cleavage of human HMW-kininogen in solution would serve this purpose. Sugo et al. (31) showed that when bovine HMW-kininogen was "activated" by limited proteolysis by bovine plasma kallikrein, it became a much more efficient cofactor of Factor XII activation than the intact form. A logical explanation of this experiment is that active HMW-kininogen adsorbs more avidly to the kaolin employed, facilitating the kallikreinmediated cleavage of Factor XII on a negatively charged surface.

The requirement for Factor XII in the proteolysis of HMWkininogen, therefore, appears to be indirect, requiring first, the conversion of Factor XII to XIIa and Factor XII fragments on a negatively charged surface, which in turn, cleaves prekallikrein to yield kallikrein. Support for this conclusion derives from the observation of greatly diminished adsorption of HMW-kininogen to kaolin from prekallikrein-deficient plasma (Fig. $1 \mathrm{~A}$ ) as well as the promotion of HMW-kininogen adsorption in Factor XIIdeficient plasma incubation of the plasma with kallikrein (Fig. 8). Moreover, when we quantified the adsorption of prekallikrein and Factor XI (zymogens requiring HMW-kininogen for optimal adsorption to negatively charged surfaces), we observed that the amount of prekallikrein (Fig. $2 A$ ) and Factor XI (Fig. $2 B$ ) in Factor XII-deficient and HMW-kininogen-deficient plasma that was adsorbed was greatly diminished, as compared with normal. Therefore, the amount of Factor XI from Factor XII-deficient plasma that adsorbed to kaolin represents the suboptimal adsorption of this zymogen, without the assistance of HMW-kininogen, since the adsorption was similar in HMW-kininogendeficient plasma. This adsorption, in the absence of HMWkininogen, however, renders the molecule markedly less active in a coagulant assay (S. Schiffman, personal communication), and less susceptible to cleavage (7). Therefore, HMW-kininogen, whether alone or complexed with either prekallikrein or Factor XI, must be cleaved before it can substantially associate with a negatively charged surface, in the presence of plasma.

It is of interest that Factor XII adsorption to kaolin from all contact-factor-deficient plasmas was similar to normal. This suggests that adsorption of Factor XII is independent of HMWkininogen as well as independent of cleavage. Furthermore, at a time when only $15 \%$ of the Factor XII from normal plasma was adsorbed, $29 \%$ of the HMW-kininogen, $65 \%$ of the prekallikrein, and $81 \%$ of the Factor XI were adsorbed, consistent with the catalytic role of Factor XII in the alteration of HMWkininogen.

It is also evident from our data, however, that there must be a second mechanism for cleavage of HMW-kininogen in plasma, since HMW-kininogen did adsorb, albeit slowly, to kaolin in prekallikrein-deficient plasma. We recently observed that in a purified system, Factor XIa can cleave HMW-kininogen (32). Furthermore, the slightly diminished HMW-kininogenadsorption from Factor XI-deficient plasma (Fig. $1 \mathrm{~A}$ ), at the lowest kaolin concentration, suggests an involvement of Factor $\mathrm{XIa}$ in the cleavage of HMW-kininogen. It is possible that the slow activation of Factor XII, which is known to occur in prekallikrein-deficient plasma (4), eventually activates enough Factor XI to cleave HMW-kininogen. Further investigations are now underway in our laboratory to determine the role of Factor XIa in HMW-kininogen cleavage and surface-adsorption in plasma. Finally, Wiggins (33) has recently shown that Factor XIIa, at stoichiometric concentrations, can cleave HMW-kininogen, but only in the presence of kaolin.

The present report demonstrates that intact HMW-kininogen is a procofactor that is activated by kallikrein. The requirement of proteolytic cleavage of a cofactor by its product to provide maximum acceleration is not unique to contact-activated coagulation. Factor $\mathrm{V}$ functions as a procofactor for the Factor Xa-catalyzed conversion of prothrombin to thrombin. Cleavage of Factor $\mathrm{V}$ by thrombin markedly enhances its coagulant activity (34), since Factor Va has increased affinity for the platelet surfaces, as compared with unaltered Factor V (35). Factor VIII:C also exists as a procofactor, which when activated by thrombin, greatly enhances the activation of Factor X by Factor IXa (36).

Certain investigators have postulated, although none has demonstrated (37), a physical complex existing between HMWkininogen and Factor XIIa on the surface in an attempt to explain the acceleration of contact-activated coagulation by HMW-kininogen. The present study, however, provides evidence for a functional, rather than physical, relationship between these two proteins. The requirement for cleavage of HMW-kininogen by Factor XII-dependent proteases, before surface adsorption, allows for the temporally ordered proximity of HMW-kininogen, with its complexed prekallikrein and Factor XI, to Factor XIIa. Viewed in this way, diffusion of kallikrein into solution (38) would allow propagation of proteolysis, not only by activation of additional amounts of Factor XII (6), but also by cleavage of HMW-kininogen, in order to maximize its cofactor activity.

\section{Acknowledgments}

We wish to thank Drs. Andrei Budzynski, Edward Kirby, and Alvin Schmaier for their constructive criticisms of this manuscript, and Monica Kollman and Dr. Linda Knight for radiolabeling HMW kininogen and tyrosyl-bradykinin. We are grateful to Dr. Andrei Budzynski for the generous gift of highly purified plasminogen-free fibrinogen and to Dr. A. David Purdon for performing the radioimmunoassay for bradykinin.

This work was supported by National Institutes of Health grants HL 14217 (Specialized Center of Research) in thrombosis and HL 24365 as well as grants from the Council for Tobacco Research Inc. 1420 and the Swiss National Science Foundation.

\section{References}

1. Thompson, R. E., R. Mandle, Jr., and A. P. Kaplan. 1977. Association of Factor XI and high molecular weight kininogen in human plasma. J. Clin. Invest. 60:1376-1380.

2. Mandle, R., Jr., R. W. Colman, and A. P. Kaplan. 1976. Identification of prekallikrein and high-molecular-weight kininogen as a complex in human plasma. Proc. Natl. Acad. Sci. USA. 73:4179-4183. 
3. Griffin, J. H., and C. G. Cochrane. 1976. Mechanism for the involvement of high molecular weight kininogen in surface-dependent reactions of Hageman factor. Proc. Natl. Acad. Sci. USA. 73:2554-2558.

4. Meier, H. L., J. V. Pierce, R. W. Colman, and A. P. Kaplan. 1977. Activation and function of human Hageman factor. The role of high molecular weight kininogen and prekallikrein. J. Clin. Invest. 60:1820.

5. Wiggins, R. C., B. N. Bouma, C. G. Cochrane, and J. H. Griffin 1977. Role of high molecular weight kininogen in surface-binding and activation of coagulation factor XI and prekallikrein. Proc. Natl. Acad. Sci. USA. 74:4636-4640.

6. Saito, H. 1977. Purification of high molecular weight kininogen and the role of this agent in blood coagulation. J. Clin. Invest. 60:584594.

7. Silverberg, M., J. E. Nicoll, and A. P. Kaplan. 1980. The mechanism by which the light chain of cleaved HMW kininogen augments the activation of prekallikrein, factor XI and Hageman factor. Thromb. Res. 20:173-190.

8. Kaplan, A. P. 1978. Initiation of the intrinsic coagulation and fibrinolytic pathways in man: the role of surfaces, Hageman factor prekallikrein, high molecular weight kininogen and factor XI. Prog. Hemostasis Thromb. 4:127-175.

9. Davie, E. W., K. Fujikawa, K. Kurachi, and W. Kisiel. 1979. The role of serine protease in the blood coagulation cascade. Adv. Enzymol. 49:277-318.

10. Jackson, C. M., and Y. Nemerson. 1980. Blood coagulation. Ann. Rev. Biochem. 49:765-811.

11. Thompson, R. E., R. Mandle, Jr., and A. P. Kaplan. 1979. Studies of the binding of prekallikrein and Factor XI to high molecular weight kininogen and its light chain. Proc. Natl. Acad. Sci. USA. 76:48264866.

12. Schapira, M., C. F. Scott, and R. W. Colman. 1981. Protection of human plasma kallikrein from inactivation by Cl-inhibitor and other protease inhibitors. The role of high molecular weight kininogen. Bio chemistry. 20:2738-2743.

13. Schapira, M., C. F. Scott, A. James, L. Silver, F. Kueppers, H. James, and R. W. Colman. 1982. High molecular weight kininogen or its light chain protects human plasma kallikrein from inactivation by plasma protease inhibitors. Biochemistry. 21:567-572.

14. Scott, C. F., M. Schapira, H. L. James, A. B. Cohen, and R. W. Colman. 1982. Inactivation of Factor XIa by plasma protease inhibitors. Predominant role of $\alpha_{1}$-protease inhibitor and protective effect of high molecular weight kininogen. J. Clin. Invest. 69:844-852.

15. Kaplan, A. P., and K. F. Austen. 1970. A prealbumin activator of prekallikrein. J. Exp. Med. 10:802-812.

16. Scott, C. F., E. Kirby, P. Schick, and R. W. Colman. 1981. Effect of surfaces on fluid-phase prekallikrein activation. Blood. 57:553-560.

17. Vroman, L., and A. L. Adams. 1969. Findings with the recording ellipsometer suggesting rapid exchange of specific plasma proteins at liquid/solid interfaces. Surface Sci. 16:438-446.

18. Schmaier, A. H., L. Silver, A. L. Adams, G. C. Fischer, P. C. Munoz, L. Vroman, and R. W. Colman. 1984. The effect of high molecular weight kininogen on surface-adsorbed fibrinogen. Thromb. Res. 33: In press.

19. Vroman, L., A. L. Adams, G. C. Fischer, and P. C. Munoz. 1980. Interaction of high molecular weight kininogen, factor XII, and fibrinogen in plasma at interfaces. Blood. 55:156-159.

20. Colman, R. W., A. Bagdasarian, R. C. Talamo, C. F. Scott, M. Seavey, J. A. Guimaraes, J. V. Pierce, and A. P. Kaplan. 1975. Williams trait. Human kininogen deficiency with diminished levels of plasminogen proactivator and prekallikrein associated with abnormalities of the Hageman factor-dependent pathways. J. Clin. Invest. 56:1650-1662.

21. Scott, C. F., C. Y. Liu, and R. W. Colman. 1979. Human plasma prekallikrein. A rapid high-yield method for purification. Eur. J. Biochem. 100:77-83.

22. Kirby, E. P., and P. J. McDevitt. 1983. The binding of bovine factor XII to kaolin. Blood. 61:652-659.

23. Kerbiriou, D. M., and J. H. Griffin. 1979. Human high molecular weight kininogen. Studies on structure-function relationships and of proteolysis of the molecule occurring during contact activation of plasma. J. Biol. Chem. 254:12020-12027.

24. Pandya, B. V., R. M. Rubin, S. A. Olexa, and A. Z. Budzynski. 1983. Unique degradation of human fibrinogen by proteases from western diamondback rattlesnake (Crotalus atrox) venom. Toxicon. 21: In press.

25. Ratnoff, O. D., and H. Saito. 1976. Evidence that Fitzgerald factor counteracts inhibition by kaolin or ellagic acid of the amidolytic properties of plasma kallikrein. Blood. 47:243-251.

26. Mancini, C., A. O. Carbonaro, and J. F. Heremans. 1965. Immunochemical quantitation of antigens by single radial immunodiffusion. Immunochemistry. 2:235-254.

27. Laemmli, U. K. 1970. Cleavage of the structural proteins during assembly of the head of the bacteriophage T4. Nature (Lond.). 227:680685 .

28. Fraker, P. C., and S. C. Speck, Jr. 1978. Protein and cell membrane iodinations with a sparingly soluble chloramide 1,3,4,6-tetrachloro-3 $\alpha$ 6a-diphenylglycoluril. Biochem. Biophys. Res. Commun. 80:849-857.

29. Proud, D., A. Togias, R. M. Naclerio, S. A. Crush, P. S. Norman, and $L$. M. Lichtenstein. 1983. Kinins are generated in vivo following nasal airway challenge of allergic individuals with allergen. J. Clin. Invest. 72:1678-1685.

30. Mori, K., and S. Nagasawa. 1981. Studies on human high molecular weight (HMW) kininogen by the action of human plasma kallikrein. J. Biochem. 89:1465-1473.

31. Sugo, T., H. Kato, S. Iwanaga, and S. Fujii. 1981. The accelerating effect of bovine plasma HMW kininogen on the surface-mediated activation of factor XII. Generation of a derivative form (active kininogen) with maximal cofactor activity by limited proteolysis. Thromb. Res. 24:329-337.

32. Scott, C. F., A. D. Purdon, L. D. Silver, and R. W. Colman. 1983. Cleavage of high molecular weight kininogen (HMWK) by plasma factor XIa. Fed. Proc. 42:1177. (Abstr.)

33. Wiggins, R. C. 1983. Kinin release from high molecular weight kininogen in the absence of kallikrein. J. Biol. Chem. 258:8963-8970.

34. Colman, R. W. 1969. The effects of proteolytic enzymes on bovine factor V. I. Kinetics of activation and inactivation by bovine thrombin. Biochemistry. 8:1438-1445.

35. Tracy, P. B., J. M. Peterson, M. E. Nesheim, F. C. McDuffie, and K. G. Mann. 1979. Interaction of coagulation factor $V$ and factor Va with platelets. J. Biol. Chem. 254:10354-10361.

36. Hutten, M. B., and Y. Nemerson. 1978. Activation of factor X by factors IXa and VIII; a specific assay for factor IXa in the presence of thrombin-activated factor VIII. Blood. 52:928-940.

37. Kato, H., T. Sugo, N. Ikari, N. Hashimoto, I. Maruyama, Y. N. Han, S. Iwanaga, and S. Fujii. 1981. Role of bovine high molecular weight (HMW) kininogen in contact-mediated activation of bovine factor XII. Adv. Exp. Med. Biol. 120B:19-37.

38. Cochrane, C. G., and S. D. Revak. 1980. Dissemination of contact activation in plasma by plasma kallikrein. J. Exp. Med. 152:608-619. 